\title{
Peran Tim Wardrobe Dalam Produksi Program di Rajawali Televisi (Periode Bulan Juli 2019)
}

\author{
Siti Marlinah ${ }^{1}$, Ramdania El Hida ${ }^{2}$, Sri Rahardian Mukjizat Sakti ${ }^{3}$ \\ ${ }^{1,2,3}$ Sekolah Tinggi Ilmu Komunikasi Indonesia Maju \\ Email correspondent: sitimarlina1197@gmail.com
}

\begin{abstract}
Abstrak
Peran wardrobe didunia pertelevisian sering kali terlupakan karena dianggap kurang berperan. Namun pada kenyatanya, wardrobe sangatlah penting dalam mewujudkan ide cerita yang dibuat oleh time kreatif. Tujuan penelitian yang dilakukan ini untuk mengetahui peran tim wardrobe dalam produksi program acara Dubi Dubi Dam di Rajawali TV dengan memfokuskan penelitian pada periode bulan Juli 2019. Metode penelitian yang digunakan iailah mengunakan studi kasus karena dalam penelitian ini ingin membahas secara khusus mengenai hal-hal yang berkenaan pada produksi program terkait dengan peran tim wardrobe.Hasil penelitian ii membahas mengenai peran yang dilakukan oleh wardrobe dalam produksi program Dubi Dubi Dam mulai dari pra produksi,produksi, hingga pasca produksi. Penelitian ini menyimpulkan bahwa peran tim wardrobe. Penelitian ini menyimpulkan bahwa pentingnya peran tim wardrobe dalam suatu program acara televisi salah satunya yaitu program acara Dubi Dubi Dam di Rajawali TV, wardrobe bertangung jawab atas kostum atau busana yang digunakan oleh Host.Karena fungsi busana atau kostum adalah untuk menarik perhatian penonton, wardrobe harus terlibat secara cara menyeluruh pada proses produksi acara Dubi Dubi Dam mulai dari pra produksi,produksi hingga pasca produksi.
\end{abstract}

Kata kunci: peran tim wardrobe,produksi,program acara televise

\begin{abstract}
Wardrobe's role in the television world is often forgotten because it is considered to be lacking a role. But in reality,wardrobe is very imprortant in realizing story ideas created by the creative team.The purpose of this research is to find out the role of the wardrobe team in the production of the Dubi Dubi Dam program in Rajawali $T v$ by focusing the research on the July 2019 period.The research method used is descriptive qualitative because in this study I want to discuss specifically about matters relating to the production of programs related to the role of the wardrobe team. The results of this study discuss the role of wardrobe in the production of the Dubi Dubi Dam program,from pre-production to post - production. This research concludes that the role of the wardrobe team this research concludes that the importance of the wadrobe team's role in a television program is one of them is the Dubi Dubi Dam program on Rajawali TV,wardrobe is responsible for the costumes or closthing used by the Host. Because the function of clothing or costumes is to attract the attention of the audience,wardrobe must be involved in the extension of the production process of the Dubi Dubi Dam program from pre-production ,production, to post- production.
\end{abstract}

Keywords: wardrobe team role,production,television program's 


\section{Pendahuluan}

Televisi adalah salah satu media komunikasi massa yang mempunyai fungsi sebagai media yang memberikan informasi, sebagai alat yang mendidik (edukatif) artinya dapat meningkatkan pengetahuan, keterampilan dan moral seseorang dan juga sebagai media yang menghibur.

Media massa sangat berperan dalam perkembangan atau bahkan pola tingkah laku menambah wawasan dari suatu masyarakat, yang tadinya tidak mengetahui informasi dengan adanya media tersebut maka bisa lebih mudah untuk mengetahui informasi yang dibutuhkan. Media yang sering digunakan oleh masyarakat Indonesia adalah media elektronik (radio dan televisi). ${ }^{1}$

Romli menjelaskan radio siaran (Broadcasting Radio) adalah salah satu jenis media massa (Mass Media), merupakan sarana atau saluran komunikasi massa (Channel of Mass Communication), seperti halnya surat kabar, majalah, atau televisi, sedangkan televisi adalah sebuah penangkap siaran yang bergambar dan bersuara yang dipancarkan melalui gelombang elektromagnetik, maka televisi merupakan alat media massa yang tampak atau dapat dilihat dari jarak jauh oleh audiens sehingga semua audiens bisa lebih cepat mendapatkan informasi dari media massa tersebut.

Kamus Besar Bahasa Indonesia menjelaskan bahwa arti "media" yaitu alat (sarana) komunikasi seperti,Koran,majalah, radio,televise,film,poster dan spanduk. Luhmann juga menjelaskan bahwa apa yang disebutkan itu pada dasarnya lebih dikenal sebagai media massa yang berarti tidak adanya interaksi diantara pengirim pesan (sender) dan penerima pesan (receiver).

Lasswell dan Wright menjelaskan tentang fungsi media massa yaitu "media massa mempunyai empat fungsi social. Keempat fungsi social tersebut adalah (1) Pengamatan Sosial, (2) Korelasi Sosial, (3) Sosialisasi, (4) Hiburan".

Televisi ialah salah satu media elektronik atau media massa yang mempunyai fungsi memberikan hiburan yang sehat kepada permirsanya, karena manusia adalah makhluk yang membutuhkan hiburan, selain menghibur televisi juga memberikan informasi. ${ }^{2}$ Televisi juga menayangkan berbagai jenis program yang beragam, Latief memberikan gambaran tentang jenis-jenis program siaran televisi yang secara umum dapat dibagi kedalam dua bagian, yaitu program informasi disebut juga program berita(News) dan program hiburan disebut juga (entertainment).

Format program (News) dibagi kedalam dua format yaitu Hard News dan Soft News. Hard News atau berita keras dibagi kedalam tiga kelompok, yaitu: (1) Straight News disebut juga dengan warta berita atau straight Newcast, yaitu berita singkat dengan hanya menyajikan informasi penting yang sedang terjadi. (2) On the spot Reporting, adalah berita berupa laporan pandangan mata dari tempat kejadian. (3) Interview On Air, merupakan wawancara dengan melihat langsung narasumber yangf diwawancarai atau hanya mendengarkan suaranya.

Soft News atau berita lunak dibagi kedalam enam kelompok yaitu: (1) Current Affair, format program yang menyajikan informasi terkait dengan suatu berita penting yang muncul sebelumnya. (2) Magazine, format program yang materinya heterogen, terdiri dari berbagai fakta dan pendapat yang dirangkai menjadi satu program. (3) Infotaiment, adalah program informasi yang menyajikan berita kehidupan orang-orang terkenal (celebrities). (4) Feature, adalah berita ringan namun menarik, tidak terkait dengan waktu (timeless). (5) Documenter, adalah program yang menyajikan cerita nyata, dilakukan pada lokasi sesungguhnya didukung narasi. (6) Sport, berita olahraga digolongkan dalam jenis berita, karena sport fakta kejadian tanpa rekayasa. ${ }^{3}$

Format program hiburan (entertainment) tersebut terbagi menjadi dua yaitu program drama dan nondrama. Nondrama format program yang sangat fleksibel, karena terdiri dari unsur drama dan jurnalistik yang dikombinasikan menjadi satu program untuk mengtahui format-format drama ini sebagai berikut: (1) Musik, merupakan program yang menyajikan musik untuk pemirsa biasanya berupa videoklip dan live music atau konser musik. (2) Permainan, adalah program yang menampilkan 
permainan atau perlombaan contohnya kuis “ Berpacu dalam melodi” (3) Reality Show, adalah program yang diproduksi berdasarkan fakta apa adanya,tanpa scenario dan arahan. (4) Pertunjukan, adalah program yang Diproduksi dengan mengandalkan keahlian dari pengisi acara, contohnya wayang, sulap, masak dll. (5) Lawak, program lawak disebut juga program komedi, namun kedua istilah format program ini berbeda. Contohnya Ovj dan OB di RCTI. (6) Variety Show, adalah format program yang memadukan berbagai format, diantaranya musik, games, tari-tarian, fashion show, dan interview, contoh dari program berformat Variety Show salah satunya "Dubi Dubi Dam" Di RTV. (7) Repackaging adalah program dengan materi video dalam bentuk shot-shot atau materi yang sudah ada. (8) Talk Show adalah program diskusi atau panel yang diikuti lebih dari satu orang pembicara atau narasumber untuk membicarakan suatu topik.

Drama kata yang berasal dari bahasa yunani dran, artinya bertindak atau berbuat, berikut jenisjenis format program: (1) Sinetron atau sinema elektronik. (2) Film. (3) Kartun.

Dalam buku television Production Handbook sebuah program statiun televisi memiliki tiga tahapan strategi dalam memproduksi suatu program televise yaitu pra produksi, produksi dan pasca praduksi ketiga tahapan tersebut merupakan awal mulanya suatu program televisi dalam mebuat suatu program yang baik untuk khalayak.

Standard Operational Procedure (SOP) berfungsi sebagai acuan dalam tahapan proses produksi, mengingat produksi program televisi merupakan pekerjaan yang melibatkan banyak orang yang memiliki keteramoilan yang berbeda-beda.

Sebuah program acara yang baik pasti ditangani oleh kerabat kerja (crew)yang baik walaupun banyak menampilkan artis atau bintang tamu,tetapi apabila tidak didukung oleh crew yang baik tidak mungkin sebuah program akan berjalan dengan baik.Untuk itu produksi memerlukan pembagian tugas yang sangat rinci denganm tanggung jawab yang jelas salah satunya ialah peran Tim Wardrobe.

Andi Fachrudin,menjelaskan Tim Wardrobe (costum designer) bertanggung jawab atas pemilihan busana yang akan dipergunakan untuk produksi seperti: meneliti dan merancang busana serta aksesoris untuk para aktris atau actor serta mengawasi penyewaan dan pemasangan tim wardrobe juga bertanggung jawab atas pemilihan busana yang akan digunakan untuk produksi, serta yang merancang busana.Tim wardrobe bukan hanya memastikan segala hal menyangkut busana baik kerapihan sampai kerusakan diperhatikan agar tidak mengganti secara besar kepada pihak sponsor terkait.

Menurut Dicky Umbara tata busana adalah seni pakaian dan segala perlengkapan yang menyertai,untuk menggambarkan tokoh,tata busana termasuk segala aksesoris dan segala unsur penting untuk menggambarkan tokoh. ${ }^{4}$

Peran Tim Wardrobe dalam produksi program televisi merupakan bagian dari department Art Support, adalah tim yang mengisi dalam proses produksi siaran televisi yang didalamnya terdapat beberapa divisi diantaranya set design,property,tim wardrobe, make up, setiap divisi memiliki tanggung jawab yang berbeda-beda,namun mereka bersatu untuk kelancaran prosese produksi program siaran.Hilang satu divisi tersebut tentunya mengurangi nilai program siaran yang layak bagi khalayak luas. ${ }^{5}$

Tujuan penelitian ini adalah untuk mengetahui bagaimana peran tim Wardrobe dalam produksi acara Dubi Dubi Dam DI Rajawali Televisi dan juga untuk mengetahui apa saja kendala yang dialami tim Wardrobe dalam produksi acara Dubi Dubi Dam DI Rajawali Televisi.

\section{Metode}

Metode penelitian yang digunakan dalam penelitian ini merupakan penelitian deskriptif dengan pendekatan kualitatif.Metode ini dipilih karena penulis ingin menguraikan serta mendeskripsikan mengenai bagaimana Peran Tim Wardrobe Dalam Produksi Acara Dubi Dubi Dam Di Rajawali Televisi (periode bulan Juli 2019). ${ }^{16}$ 
Penelitian ini menggunakan deskriptif kualitatif,. Deskriptif adalah suatu pendekatan dalam meneliti status kelompok manusia, obyek, suatu kondisi, suatu system pemikiran ataupun suatu kilas peristiwa pada masa sekarang. Sedangkan kualitatif menurut Bogdan dan Taylor adalah suatu prosedur penelitian yang menghasilkan data deskriptif berupa kata-kata tertulis dan lisan dari orang dan perilaku yang diamati.

Melalui penelitian kualitatif, peneliti dapat mengenali subjek dan merasakan apa yang mereka alami dalam kehidupan sehari-hari, untuk melengkapi data, peneliti menggunakan berbagai metode pengumpulan data, seperti wawancara, pengamatan, serta penelitian dokumen dan arsip.

Melalui penelitian deskriptif kualitatif, peneliti merasa tidak ada jarak antara peneliti dengan sumber informasi atau responden, sehingga peneliti dapat lebih menyatu dengan penelitian guna menjawab fenomena yang peneliti temukan pada institusi terkait, serta memahami obyek yang diteliti secara mendalam.Pendekatan kualitatif adalah sebagai sumber penelitian yang menghasilkan data deskriptif berupa kata-kata tertulis atau lisan dari orang-orang dan perilaku yang dapat diamati. Dan,metode deskriptif ini merupakan penelitian yang menghasilkan suatu uraian mendalam tentang apa yang dilihat,ditulis, atau lisan,didengar,dan tingkah laku dari suatu individu atau kelompok masyarakat kemudian penulis baru mendata sepintas mengenai informasi yang diperoleh. ${ }^{6}$

Sifat penelitian ini menggunakan metode deskriptif kualitatif, metode ini digunakan karena penulis merasa tidak ada jarak anatar penulis kepada sumber informasi atau responden dalam menggali8 sebuah informasi sehingga penulis memiliki ruang untuk memahami objek yang diteliti secara mendalam, sehingga penulis ingin membahas secara khusus hal-hal yang berkaitan dengan peran tim wardrobe dalam produksi program acara Dubi Dubi Dam di Rajawali Televisi (periode bulan Juli 2019).

Data yang digunakan dalam penelitian ini dengan menggunakan data primer merupakan hasil dari menelitian atau observasi dengan teknik wawancara secara mendalam dan sekunder hasil dari pencarian,dari tinjauan studi kepustakaan seperti buku atau jurnal terdahulu, dan teknik pengumpulan data yang digunakan ialah,observasi atau pengamatan secara langsung dalam berkelangsungannya praktek kerja,wawancara sama dengan mengajukan sebuah pertanyaan yang berkaitan dengan rumus masalah dan dokumentasi berupa file-file ataupun foto-foto hingga teknik pengelolaan data dan analisis data menggunakan reduksi tahap ini penulis memilih informasi mana yang relevan,penyajian data dan menyajikan data berupa uraian ataupun table,dan pengambilan kesimpulan merupakan penarikan kesimpulan dari hasil yang didapatkan.

\section{Hasil dan Pembahasan \\ Sejarah RTV}

RTV (disingkat dari Rajawali Televisi, sebelumnya bernama B-Channel) adalah sebuah stasiun televisi swasta nasional di Indonesia yang dimiliki oleh Rajawali Corpora. RTV resmi mengudara pada tanggal 1 November 2009 di Jakarta dengan nama B-Channel. Saat ini program RTV sendiri lebih difokuskan pada acara hiburan, soft news dan variety show untuk keluarga Pada tanggal 3 Mei 2014, B-Channel berganti nama menjadi RTV. Nama RTV diluncurkan pada 3 Mei 2014 menggantikan nama B-Channel setelah mengalami transformasi besar dan peningkatan oleh manajemen baru, B-Channel sendiri telah diperkenalkan pada November 2009. Hingga saat ini, RTV sudah memiliki lebih dari 30 stasiun di kota-kota Indonesia, sejak kelahirannya kembali RTV telah memulai berbagai langkah terobosan, antara lain, saluran itu secara terbuka mengumumkan untuk menargetkan pemirsa perempuan sebagai segmen pasar utama, namun setelah melakukannya, menyediakan program yang juga disukai oleh pemirsa pria, serta anak-anak, adalah fokus utama RTV.

RTV didirikan pada tahun 2008 dengan nama B-Channel oleh Sofia Koswara, seorang pengusaha mebel dari Cikarang. B-Channel memulai siaran percobaannya pada tahun 2008 dan diluncurkan pada tanggal 1 November 2009. Sofia Koswara mendirikan B-Channel dengan bertujuan untuk menebarkan 
virus inspirasi untuk keluarga. Pada saat itu B-Channel merupakan sebuah stasiun televisi lokal di Jakarta yang merelai siaran TVN. Pada tanggal 1 Januari 2011, Lanny Rahardja menjabat sebagai direktur utama B-Channel meluncurkan logo barunya yang menggambarkan semangat yang baru dalam memberikan inspirasi bagi seluruh keluarga (juga logo-logo lokal yang berjaringan dengan B-Channel). Di saat yang sama, B-Channel resmi diluncurkan sebagai stasiun televisi berjaringan ditayangkan tanpa jeda komersial mulai melebarkan sayapnya ke satelit Palapa. Pada tahun 2012, perusahaan konglomerat Rajawali Corpora mengakuisisi 100\% dari saham B-Channel. Di saat itu juga B-Channel menggandeng beberapa televisi berlangganan. Pada tanggal 1 Oktober 2012, B-Channel mengganti slogannya menjadi Inspirasi Anda.

Pada awal tahun 2013, 5 televisi lokal jaringan B-Channel mengubah namanya menjadi BChannel disusul beberapa kota lainnya pada pertengahan hingga akhir tahun 2013. Hal ini membuat bahwa B-Channel telah bersiap untuk menjadi sebuah stasiun televisi nasional. Pada pertengahan tahun 2013, B-Channel bekerjasama dengan TVKU yang dimiliki oleh Universitas Dian Nuswantoro untuk menyiarkan siarannya di Semarang karena Kartika TV di Pati tidak bisa dijangkau oleh pemirsa di Semarang, pada akhir tahun 2013 B-Channel mendirikan pemancar di Sukabumi.

Pada awal tahun 2014, Maria Goretti Limi menggantikan Lanny Rahardja sebagai direktur utama B-Channel setelah pindah dari antv, pada tanggal 3 Mei 2014, B-Channel resmi mengakhiri siarannya dan berubah nama menjadi RTV pada saat acara Grand Launching Langit Rajawali, pada saat yang sama semua televisi lokal jaringan B-Channel juga berubah nama menjadi RTV (kecuali TVKU), dan CT Channel menyusul 2 hari setelahnya.

Pada tanggal 7 April 2015, RTV merelai siaran MTV Indonesia pada waktu tertentu di seluruh jaringannya, tetapi pada tanggal 10 April 2015, RTV tidak lagi menyiarkan siaran MTV Indonesia dikarenakan masalah teknis. Pada tanggal 31 Mei 2015, RTV merayakan ulang tahun pertamanya di Surabaya yang bertajuk Setahun di Langit RTV. Wali Kota Surabaya Tri Rismaharini juga hadir dalam acara tersebut. Pada bulan September 2015, Maria Goretti Limi sudah tidak menjabat lagi sebagai direktur utama RTV dan digantikan oleh Satrio Tjai yang ditunjuk oleh Rajawali Corpora.

Pada bulan Oktober 2015, RTV mendapat hak siar Piala Dunia U-17 FIFA 2015. Pada tahun 2016, RTV berhasil menjangkau Semarang dengan saluran 56 UHF dan pada akhirnya, TVKU resmi memisahkan diri dari RTV setelah bergabung selama kurun waktu 3 tahun dari tanggal 1 Juli 2013 hingga 30 Juni 2016. Pada tanggal 9 Mei 2017, RTV mendapat hak siar untuk menyiarkan seluruh pertandingan Piala Konfederasi FIFA 2017 dan 4 pertandingan Piala Dunia U-20 FIFA 2017.

Pada tanggal 19 Mei 2017, dalam rangka merayakan hari ulang tahun ketiga RTV, RTV menayangkan sebuah teater musikal bertajuk Pesta Sahabat yang saat ini telah menghasilkan sejumlah sekuel. Pada bulan Desember 2017, RTV mendapat hak siar untuk kejuaraan balap mobil listrik Formula E periode 2017/2018. Pada Februari 2018, RTV meresmikan sebuah studio mini di KidZania Jakarta, dengan peralatan yang sama dengan peralatan studio televisi pada umumnya. Pada tanggal 3 Mei 2019, dalam rangka merayakan hari ulang tahun kelima RTV, RTV menayangkan sebuah teater musikal bertajuk RTV 5 Makin Cakep :Hey Tayo yang menampilkan kolaborasi para pengisi acara Pesta Sahabat dengan tokoh-tokoh dari serial animasi Tayo the Little Bus. Disiarkan langsung dari Taman Mini Indonesia Indah, teater musikal ini juga dimeriahkan oleh Ada Band, Marion Jola, Enda, Zara Leola, Nola, Naura, Neona, Nita Thalia dan masih banyak lagi. Pada saat yang sama, RTV juga meluncurkan maskot barunya, yaitu Rio, menggantikan maskot lamanya yaitu Mr. Ravi yang dipergunakan dari tahun 2014.

Dubi Dubi Dam merupakan salah satu program Variety Show, sebuah program acara music anakanak yang berfokus pada pelestarianm music anak Indonesia. Dubi Dubi Dam merupakan salah satu program Variety Show unggulan di RTV. Pada setiap segment atau rubiknya berisi tayangan yang mendidik dan menghibur.Berdurasi 60 menit, yang terdiri dari 4 segment yaitu Dubi Dam Club 
(Kamera Dubi dan Joget Dubi), Hallo Dubi, Remote Dubi, dan Mailbox dari penonton Dubi dirumah.Dan dipandu oleh 4 Host, yaitu Jane Callista, kakak Novi Herlina, kakak Hira dan kakak Angga.Untuk Host cadanga jika suatu saat Host utama berhalangan hadir biasanya nanti digantikan oleh Host lain, yaitu kakak Onanad dan Alifa Lubis. ${ }^{7}$ Dubi Dubi Dam memiliki empat rubric, yaitu:

1. Dubi Dubi Dam (Reguler LIVE Studio)

2. Dubi goes to school (tapping syuting dilakukan disekolah yang terpilih untuk dikunjungi )

3. Dubi goes to mall (audisi untuk sahabat dubi yang memiliki bakat)

4. Dubi on vacation (tapping syuting dilakukan ditaman bermain atau wiisata ke luar kota )

Stasiun televisi adalah tempat kerja yang sangat kompleks yang melibatkan banyak orang dengan berbagai jenis keahlian masing-masing. Seperti produser, kameraman ,tim kreatif, editor dan staf operasional lainnya yang harus saling berinteraksi dan berkomunikasi dalam upaya untuk menghasilkan suatu program yang sebaik mungkin.

Sebuah program acara yang baik pasti ditangani oleh seorang sutradara yang baik, seseorang cameramen yang baik. Walaupun sebuah program banyak menampilkan "bintang atau artis" yang baik, tetapi apabila tidak didukung oleh kerabat kerja (crew) yang baik, tidak mungkin sebuah program akan berhasil baik. Kerabat kerja yang baik mutlak diperlukan dalam sebuah produksi program. Masingmasing kerabat kerja harus professional dalam bidang dan mampu bertanggung jawab sungguhsungguh pada tugasnya untuk itu, produksi memerlukan pembagian tugas yang sangat rinci dengan tanggung jawab yang jelas. ${ }^{8}$ Siapa saja tim produksi dan apa saja tanggung jawabnya berikut uraiannya:

1. Executive Producer

Lini teratas dibagian fungsional yang bertanggung jawab penuh terhadap program-program dibawahnya. Seorang EP harus mampu memimpin dan mengelola program maupun tim yang ada di bawahnya, bahkan harus terjun langsung pada saat kondisi darurat dimana produser pelaksana program berhalangan saat shooting berlangsung.

2. Produser

Produser merupakan bagian fungsional yang langsung dibawah EP dan berkewajiban dalam program mulai dari pra produksi,produksi, pasca produksi sampai materi siap ditayangkan.

3. Assistant Produser

Apabila produser sibuk dantidak menungkinkan mempersiapkan sendiri administrasi program maka asisten produksi akan membantu proses tersebut mulai dari pra produksi,produksi, pasca produksi.

4. Creative

Orang yang membantu produser yang bertugas mengi9nterpretasikan naskah kedalam bentuk audo visual, pola pikirnya harus mengingat kepentingan khalayak dan sejalan dengan pemikiran produser. Seorang tim kreatif harus mampu bekerja sama dengan pihak lain, mendengarkan dan menerima pendapat orang lain yang mendukung proses produksi, seta menjadi pengambil keputusan yang tepat. Betanggung jawab terhadap hasil kerjanya. Seorang tim kratif juga harus mampu mengarahkan artis, mampu mengarahkan kameraman, mapu mengarahkan tata cahya, mengerti dan mengarahkan tata suara, mengarahkan dan mengerti tata artistic, mengarahkan kostum, make up, set dekor, property, PERAN tim kreatif sangat diperlukan karena adanya tim kreatif membantu kesinambungan antara bahasa tulisan yang diwujudkan dalam proses memvisualisasikan.

5. Administration / Budget Officer / Unit Manager

Bersama dengan produser mangestimasikan budget untuk keperluan semua ini. Apabila disetujui unit manager bersama produser manager uang atau ouline segmen. ${ }^{9}$ 
1. Director (Pengarah Acara)

Berugas menginterprestasikan naskah seorang produser, menjadi suatu bentuk dan susunan gambar maupun susunan suara dan menghasikan story board juga menjadi eksekutor di lapangan.

2. Floor Director

Bertindak sebagai tangan kanan Director (pengarah acara) yang menyampaikan apa yang diinginkan sutradara kepada kerabat-kerabat kerja yang bertugas dan artis pendukung dalam bentuk tanda-tanda saat akan dimulai dan berakhirnya produksi suatu acara. ${ }^{10}$

3. Lighting Director

Bertanggung jawab terhadap keberhasilan penataa cahaya distudio baik secara artistic maupun menyentuh perasaan yang sesuai dengan tuntutan naskahnya.

4. Audioman (penata suara)

Seoarang penata suara akan mengatur pertimbangan suara yang dating dari berbgai sumber, dengan jalan melakukan perakayasan dalam penempatan mikropon dan sebagainya. ${ }^{11}$

5. Cameraman

Seorang kameramen merupakan tangan kanan seorang pengarah acara karena itu harus mempunyai hubungan batin yang kuat diantara mereka agar memudahkan, mencernakan dan menginterprestasikan rasa seni yang dimiliki seorang pengarah acara.

6. Switcherman

Bertanggung jawab terhadap pergantian gambar baik atas permintaan sutradara atau sesuai dengan shooting script yang telah disusun sebelumnya.

7. Control Room Person

Orang yang bertanggung jawb terhadap pengoperasian seluruh peralatan yang terdapat diruang control seperti:CCU, VTR, CG, Vision Mixer, dan lain-lain

8. Editor

Orang yang bertanggung jawab terhadap pengoperasian mesin editing dalam proses produksi. Seorang editor harus bisa membuat atau membantu dalam proses kreatifitas proses editing. ${ }^{12}$

Penelitian ini membahas pada periode bulan Juli alasannya karena pada bulan Juli proses produksinya berbeda tidak seperti pada bulan biasanya karena selama empat minggu proses produksi program Dubi Dubi Dam yang dilaksanakan setiap hari kamis secara Live serta setelah itu melakukan syuting tapping untuk kebutuhan ditayangkan pada hari jumat. ${ }^{13}$

Perbedaan yang terjadi pada proses produksi program Dubi Dubi Dam dibulan Juli dengan bulan lainnya yaitu terletak pada tema dan juga busana yang dinginkan tim kreatif lebih berkarakter,serta memiliki ide cerita yang lebih menarik pada bulan Juli karena mungkin bertepatan pada hari libur sekolah maka tema dan ide cerita dibuat cukup berbeda dengan periode pada bulan sebelumnya mulai dari tema,kostum atau busana yang diminta oleh tim kreatif lebih berkarakter sangat berbeda tidak seperti permintaan busana atau kostum pada saat shooting pada bulain lainnya yang hanya menggunakan busana atau kostum blus dengan warna-warna collorfull serta menggunakan bawahan rok tutu dan tidak lupa setoking dengan warna yang soking. ${ }^{14}$

Wardrobe yang digunakan oleh program acara Dubi Dubi Dan memiliki ciri khas wardrobe yaitu collorfull dan rok tutunya,oleh sebab itu mengapa penulis lebih tertarik untuk membahas program Dubi Dubi Dam di bulan Juli karena pada periode ini permintaan dari tim kreatif untuk busana atau kostum lebih berkarakter membuat penulis lebih merasa tertantang karena dibutuhkan persiapan khusus dibandingkan pada shooting live regular di bulan biasannya karena pada saat itu penulis terjun langsung untuk mengurus proses mulai dari pra produksi,produksi hingga pasca produksi itu sebabnya penulis lebih fokus membahas penelitian pada periode bulan Juli. 
Hasil penelitian yang dilakukan oleh peneliti saat melakukan observasi dan terjun secara langsung yaitu ikut terkait dalam proses produksi dapat disimpulkan, wardrobe memiliki peran yang tidak kalah penting dengan divisi lainnya. Keberadaan wardrobe bertanggung jawab sepenuhnya, terhadap penampilan fisik host yang aka nada dalam visual televisi.Busana atau kostum sangat diperlukan, selain untuk mendukung keindahan tayangan,busana atau kostum juga mampu menggambarkan identitas host. Wardrobe merupakan bagian dari department support yang memiliki peran penting untuk mengvisualisasikan dan merealisasikan konsep tim kreatif, maka dari itu, wardrobe memiliki peran penting saat proses produksi program tv dari mulai pra produksi,produksi hingga pasca produksi. ${ }^{15}$

Kesuksesan merupakan tujuan utama dari dibuatnya acara,banyak tim yang terlibat dalam proses produksi program televisi, seperti tim kreatif,tim cameraman,tim lighting dan masih banyk lagi setiap bagian memiliki tanggung jawabnya masing-masing seperti halnya tim department support juga memiliki bagian-bagian penting didalamnya yaitu unit manager produksi,talent,admin,make up, inventory wardrobe, dan wardrobe, tim department support bertanggung jawab menyediakan kebutuhan-kebutuhan produksi sesuai dengan konsep dan keinginan dari produser serta kreatif, sesuai dengan standart operasional prosedur, proses produksi program tv dibagi menjadi tiga yaitu pra produksi, produksi, dan pasca produksi.

Tahapan yang pertama adalah pra produksi, pada tahapan ini tugas wardrobe adalah mengembangkan breakdown, stelah mendapatkan breakdown dari tim kreatif, wardrobe akan menganalisis busana atau kostum apa saja yang harus disediakan dari breakdown wardrobe bisa mengetahui tema kostum seperti apa yang sesuai dengan cerita pada setiap episodenya.Sebelum melakukan pencarian kostum,wardrobe harus mengetahui host yang akan membawakan acara, karena ukuran sizenya berbeda-beda maka wardrobe harus bisa memilih busana atau kostum apa yang cocok.

Berikutnya adalah tahapan perencanaan dan pencarian busana tau kostum, yaitu wardrobe mencari busana atau kostum ke sponsor dan tempat penyewaan kostum, setelah wardrobe mendapatkan kostum atau busana yang sesuai,apabila busana didapat dari sponsor maka wardrobe akan mengajukan surat kerjasama,namun apabila busana atau kostum harus menyewa maka wardrobe harus membuat estimasi budget. Surat kerjasama sdan estimasi budget harus disetujui oleh produser atau manager support setelah mendapat persetujuan maka wardrobe akan melakukan pengambilan busana atau kostum tersebut.Selanjutnya adalah tahapan persipan, pada tahapan ini wardrobe melakukan mix and match busana. Mix and match yang dilakukan agar busana atau kostum lebih menarik, pada tahapan ini wardrobe melakukan pemilihan aksesoris, stocking dan juga sepatu yang akan dogunakan host.

Tahapan produksi, dalam tahapan ini wardrobe bertugas untuk mengganti busana host sesuai dengan susunan episode, kemudian wardrobe standby di studio untuk melakukan touch up terhadap busana atau kostum yang digunakan host. Touch up dilakukan agar busana atau kostum terlihat rapih dikamera, sebelum shooting dimulai wardrobe mengambil foto host sebagai tanda bukti untuk sponsor jika menggunakan busana atau kostum dari sponsor dan juga harus dikirim ke grup whats app tim wardrobe sebagai evaluasi. Selama proses shooting berlangsung wardrobe bertanggung jawab mengawasi busana atau kostum yang digunakan host.

Pada tahapan pasca produksi, wardrobe melakukan pengecekan ulang terhadap busana atau kostum serta aksesoris yang digunakan oleh host untuk menghindari kehilangan, setelah itu memilih setiap busana yang digunakan untuk proses laundry sesuai dengan jenis bahan dan brand agar busana yang telah digunakan tidak rusak atau cacat pada saat proses laundry, setelah proses laundry selesai, maka wardrobe bertanggung jawab untuk mengembalikan busana atau kostum kepada sponsor dan juga ke tempat penyewaan. 


\section{Kesimpulan}

Kesimpulannya ialah bahwa Department Support khusunya wardrobe memiliki pengaruh dalam mengsukseskan sebuah program acara televisi memiliki peran penting dalam setiap tahapan proses produksi mulai dari pra produksi hingga pasca produksi. Peran wardrobe sangat berpengaruh guna tersampainya pesan suatu program acara kepada penonton dan merealisasikan konsep ide dari tim kreatif serta membuat host terliat menarik di depan layar kaca dengan busana dan kostum yang digunakan.

Tim wardrobe memiliki peran yang penting dalam suatu program acara televisi, salah satunya program Dubi Dubi Dam.Pada program ini wardrobe dituntut untuk bisa memenuhi kebutuhan busana yang berbeda-beda setiap episodenya,pada program Dubi Dubi Dam wardrobe bertanggung jawab atas terrealisasinya konsep busana atau kostum supaya dapat menciptakan suatu karakter dalam cerita yang dibawakan pada setiap episodenya.

Selain itu wardrobe juga bertanggung jawab untuk memperindah penampilan host agar menarik secara kasat mata ditelevisi yang dilihat oleh penonton, sehinga dalam pemilihan busana atau kostum tidak hanya ditentukan oleh kenyamanan host dalam menggunakannya ataupun bagus pada saat terlihat langsung oleh mata, namun mata kamera dan mata manusia secara langsung berbeda,sehingga yang menurut wardrobe bagus belum tentu dilayar televisi terlihat bagus. Dalam proses produksi program Dubi Dubi Dam di Rajawali Televisi, masing-masing divisi memiliki peran penting yang komplek,seperti tim department support, tim kreatif, tim kameraman, dan tim lightigman,semuanya berkesinambungan saatu sama lainnya karena televisi merupakan suatu pekerjaan yang dilakukan dengan kerjasama tim maka masing-masing divisi berperan penting dalam terciptanya suatu program acara televisi yang berkualitas.

Hasil penelitian yang dilakukan oleh peneliti saat melakukan observasi dan terjun secara langsung yaitu ikut terkibat dalam proses produksi dapat disimpulkan, wadrobe memiliki peran yang tidak kalah penting dengan divisi lainnya. Keberadaan wadrobe bertanggun jawab sepenuhnya, terhadap penampilan fisik Host yang aka nada dalam visual televisi.

Busana atau kostum sangat diperlukan, selain untuk mendukung keindahan tayangan, busana atau kostum juga mampu menggambarkan identitas Host.

Wadrobe merupakan bagian dari department support yang memiliki peran penting untuk mengvisualisasikan dan merealisasikan konsep tim kreatif,maka dari itu, Wardrobe memiliki peran penting saat proses produksi program tv dari mulai pra produksi, produksi, pasca produksi.

Kesuksesan merupakan tujuan utama dari dibuatnya acara. Banyak tim yang terlibat dalam proses produksi program televisi. Seperti tim kreatif, tim cameraman,tim lighting, dan masih banyak lagi. Setiap bagian memiliki tanggung jawabnya masing-masing. Tim department support juga memiliki bagian-bagian penting didalamnya yaitu Unit Manager Produksi, Talent, Admin, Make up, Inventory Wadrobe, dan Wadrobe. Tim department support bertanggung jawab menyediakan kebutuhankebutuhan produksi sesuai dengan konsep dan keinginan dari produser dan kreatif. Sesuai dengan standart operasional prosedur, proses produksi program TV dibagi menjadi tiga yaitu pra produksi, produksi dan pasca produksi.

\section{References}

1. Anton Mabruri. Penulisan Naskah Tv Program Acara Format Acara Televisi Nondrama,News Spot. Depok: publishing house; 2009.

2. Ashadi Siregar. Menyikapi Media Penyiaran. Yogyakarta: LP3Y; 2015.

3. Budiono. Kamus Lengkap Bahasa Indonesia. Jakarta: Pernebit Karya Agung; 2015.

4. Dicky Umbara. Seni Mengasah Tata Artistik Dan Memahami Bahasa Seni. Bandung: PT, Remaja Rosdakarya; 2001.

5. Efenddy OU. Ilmu Komunikasi Dan Teori Dan Praktek. Bandung: PT Remaja Rosdakarya; 2005. 


\section{JIKOM \\ Jurnal Ilmiah Komunikasi}

Volume 13, No.01, Maret. 2021

6. fred wibowo. Teknik Televisi Produksi. Yogyakarta: Pinus Book Publishe; 2007.

7. Morissan. Media Penyiaran Strategi Mengelola Radio \& Televisi. Jakarta: kencana; 2008.

8. Herbert Zettl. Television Production Handbook TenthEdition. USA: WadsWorth Cengage Learning; 2012.

9. Nartama Rukmanda. Menjadi Sutradara Televisi. Jakarta: Grasindo; 2006.

10. Permadi D. Buku Pintar Televisi. Bogor: Ghalia Indonesia; 2011.

11. Saharsaputra U. Metode Penelitian Pendekatan Kuantitatif, Kualitatif, Dan Tindakan. Bandung: Refika Aditama; 2014.

12. Siti Nurfatitah. Produksi Program Televisi (Study Kasus Acara Variety Show Dahsyat RCTI. banten: Universitas Sultan Ageng Tirtayasa; 2015.

13. Soerjono Soekanto. Sosiologi Suatu Pengantar. Jakarta: PT. Raja Grafindo Persada; 2017.

14. Sugiyono. Metode Penelitian Kuantitatif Kualitatif Dan R\&D. Bandung: alfabeta; 2012.

15. Tamburaka. Agenda Setting Media Massa. Bandung: Rajawali Pers; 2012.

16. Fatimah, et al. Komunikasi Persuasif Agen Asuransi Dalam Merekrut Calon Agen (Studi Kasus Tentang Perekrutan Calon Agen Dalam Meningkatkan Penjualan Polis di Asuransi PT. AXA). Jurnal Ilmiah Komunikasi (JIKOM) STIKOM IMA, 2018, 10.02: 110-116. 